\title{
PKA activation and endothelial claudin-5 breakdown in the schizophrenic prefrontal cortex
}

\author{
Keisuke Nishiura1,*, Naoki Ichikawa-Tomikawa ${ }^{1, *}$, Kotaro Sugimoto ${ }^{1}$, Yasuto \\ Kunii',3, Korehito Kashiwagi' ${ }^{1}$, Mizuko Tanaka1, Yuichi Yokoyama4, Mizuki Hino ${ }^{2}$, \\ Takashi Sugino ${ }^{5}$, Hirooki Yabe ${ }^{2}$, Hitoshi Takahashi ${ }^{4}$, Akiyoshi Kakita ${ }^{4}$, Tetsuya \\ Imura $^{1,6}$ and Hideki Chiba ${ }^{1}$ \\ ${ }^{1}$ Department of Basic Pathology, Fukushima Medical University School of Medicine, Fukushima, Japan \\ 2 Department of Neuropsychiatry, Fukushima Medical University School of Medicine, Fukushima, Japan \\ ${ }^{3}$ Department of Psychiatry, Aizu Medical Center, Fukushima Medical University, Fukushima, Japan \\ ${ }^{4}$ Department of Pathology, Brain Research Institute, Niigata University, Niigata, Japan \\ ${ }^{5}$ Department of Diagnostic Pathology, Shizuoka Cancer Center, Shizuoka, Japan \\ ${ }^{6}$ Department of Surgical Pathology, Kyoto Prefectural University of Medicine, Kyoto, Japan \\ * These authors contributed equally to this work \\ Correspondence to: Hideki Chiba, email: hidchiba@fmu.ac.jp \\ Keywords: blood-brain barrier; tight junction; claudin; protein kinase A; schizophrenia; Pathology Section \\ Received: August 30, $2017 \quad$ Accepted: October 04, $2017 \quad$ Published: October 16, 2017
}

Copyright: Nishiura et al. This is an open-access article distributed under the terms of the Creative Commons Attribution License 3.0 (CC BY 3.0), which permits unrestricted use, distribution, and reproduction in any medium, provided the original author and source are credited.

\section{ABSTRACT}

Schizophrenia is thought to be caused by a combination of genetic and environmental factors; however, its pathogenesis remains largely unknown. Here, we focus on the endothelial tight-junction protein claudin-5 (CLDN5), because the CLDN5 gene is mapped to the schizophrenia-associated 22q11.2 deletion region, and a single nucleotide polymorphism in the CLDN5 locus is also linked to schizophrenia. We show, by RT-qPCR and immunohistochemistry, that the expressions of CLDN5 mRNA and protein are significantly increased and decreased, respectively, in the schizophrenic prefrontal cortex (PFC) compared with control PFC. These changes were not observed in the schizophrenic visual cortex (VC), and neither the density nor diameter of the CD34-positive microvessels was altered in the schizophrenic PFC or VC. Interestingly, protein kinase A (PKA) was activated in the microvascular and perivascular regions of the schizophrenic PFC, and the PPKA-positive microvascular endothelial cells occasionally exhibited focal loss of CLND5. Since we previously demonstrated that CAMP induced CLDN5 mRNA expression and size-selective loosening of the endothelial barrier in PKA-independent and -dependent manners, respectively, a similar mechanism could contribute to the discrepancy between mRNA and protein expression of CLDN5 in the schizophrenic PFC. Taken collectively, these findings provide novel insights into the pathophysiology of schizophrenia.

\section{INTRODUCTION}

Schizophrenia is a complex psychotic disorder with an estimated prevalence of nearly 1\% [1]. Among cortical areas that are functionally and/or structurally affected in schizophrenia, the dorsolateral prefrontal cortex (PFC) is most commonly involved, and its volume is markedly decreased in the chronic state [2, $3]$. One of the strongest established genetic risk factors is the $22 \mathrm{q} 11.2$ microdeletions that cause $22 \mathrm{q} 11.2$ deletion syndrome (also known as velocardiofacial syndrome or DiGeorge syndrome) [4-6]. Indeed, the risk of developing schizophrenia rises 20 -fold in individuals with 22q11.2 microdeletions [7], strongly suggesting that the region overlapping 90 genes contains one or more susceptibility genes for schizophrenia [8,9]. Although genetic and environmental factors increase the risk of schizophrenia [10-12], the pathophysiology remains poorly understood. 
The blood-brain barrier (BBB) highly limits the movement of molecules, ions, and cells between the blood circulation and the central nervous system to protect the brain. Brain microvascular endothelial cells (BMVECs) possessing well-developed tight junctions are primarily critical for the $\mathrm{BBB}$, though the surrounding components, such as pericytes, astrocytic endfeet, and basement membranes that consist of various extracellular matrix proteins, also contribute to the establishment of the BBB [13-16]. Breakdown of the BBB has been reported in various neurological disorders, including brain ischemic stroke, edema, infections, epilepsy, multiple sclerosis, Alzheimer's disease, and Parkinson's disease [14, 15, 17, $18]$.

An association between the BBB dysfunction and schizophrenia has also been proposed [19, 20]. Interestingly, the Claudin-5 (CLDN5) gene, whose product represents the major component of barrier-forming tight junctions in endothelial cells $[21,22]$, is mapped to the $22 q 11.2$ deletion region [8, 9]. In fact, CLDN5 was originally identified as a transmembrane protein deleted in velocardiofacial syndrome (TMVCF) [23]. A single nucleotide polymorphism located in the 3 '-untranslated region of the $C L D N 5$ locus is also related to schizophrenia $[24,25]$.

CLDNs are capable of forming tight-junction strands [26], and thus the backbone of the tight junctions. Among the members of the CLDN family, CLDN5 is indispensable for the BBB. CLDN5-deficient mice exhibit a size-selective loosening of the $\mathrm{BBB}$ against small molecules (less than $800 \mathrm{Da}$ ), and die within $10 \mathrm{~h}$ after birth [22]. We previously demonstrated that cAMP activated gene expression of CLDN5 in porcine BMVECs in a protein kinase A (PKA)-independent manner [27]. We also uncovered that a phosphorylation site of human and mouse CLDN5 for PKA, Thr207 (RRPT) in the cytoplasmic terminal domain, was responsible for a sizeselective loosening of the endothelial barrier against small molecules [28].

Therefore, in the present study, we compared CLDN5 mRNA levels and CLDN5- or pPKA-positive fields as well as the diameter and density of BMVECs in both the PFC and visual cortex (VC) between schizophrenic and control specimens. Our results highlight that immuno-reactive signals for CLDN5 and pPKA are prominently diminished and induced, respectively, in the microvascular regions of the schizophrenic PFC.

\section{RESULTS}

\section{Expression of CLDN5 mRNA is increased in the schizophrenic PFC}

We first determined by RT-qPCR the expression levels of CLDN5 mRNA in control and schizophrenic brain tissues (Figure 1A). CLDN5 mRNA levels in the schizophrenic PFC samples were significantly increased compared with those in the control PFC specimens. On the other hand, there were no obvious differences in the expression levels of CLDN5 transcripts between the schizophrenic and control VC. Thus, expression of CLDN5 mRNA was enhanced in a brain region-specific manner of schizophrenia.

\section{CLDN5-immunoreactive area is decreased in the schizophrenic PFC gray matter}

We next evaluated by immunohistochemistry the expression of CLDN5 protein in control and schizophrenic cortical regions. CLDN5 was observed in the cortical microvessels of both the control and schizophrenic brain tissues, showing that the endothelial-specific distribution is maintained in schizophrenia. Interestingly, however, CLDN5-positive signals in the PFC gray matter of the schizophrenic group were decreased compared with those of the controls, and occasionally exhibited discontinuous staining patterns (Figure 1B). Such changes were not apparent in the PFC white matter, nor the VC white or gray matter. We therefore quantified the CLDN5immunoreactive area in each cortical region of the control and schizophrenic groups. As shown in Figure 1C, the CLDN5-positive field in the PFC gray matter of schizophrenic subjects was significantly diminished compared with that of the controls. By contrast, no significant differences were detected in other brain regions examined between both groups. In addition, the proportion of CLDN5 disappearance in the vessel length axis of the PFC gray matter of schizophrenic subjects was significantly increased compared with that of the controls (Figure 1D). The CLDN5-immunopositive fraction in the gray matter was higher than that in the white matter in both groups, which is likely to reflect differences in microvessel density between the gray and white matter, as shown below.

\section{Microvessel density and diameter are not altered in schizophrenia}

To exclude the possibility that the decreased CLDN5-positive field in the schizophrenic PFC gray matter could be due to a lower density in its microvessels, serial sections were immunostained with the endothelial marker CD34, and both the density and diameter of the microvessels were quantified (Figure 2A-C). No significant differences were detected in the microvessel density or diameter of each brain region examined between the control and schizophrenic groups as reported previously [29, 30], strongly suggesting that the expression of CLDN5 protein was selectively reduced in the schizophrenic PFC gray matter. The microvessel densities 
A

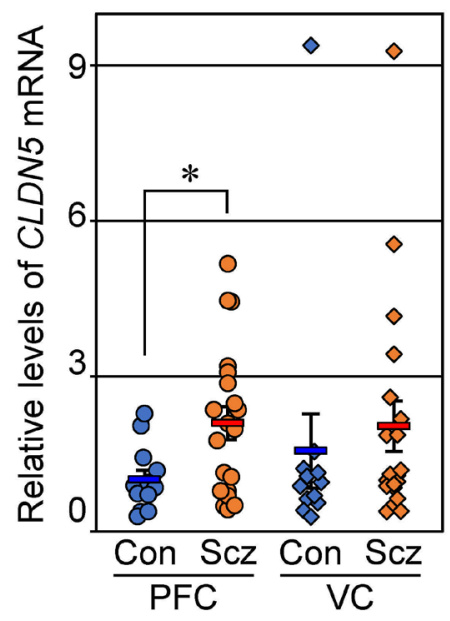

B

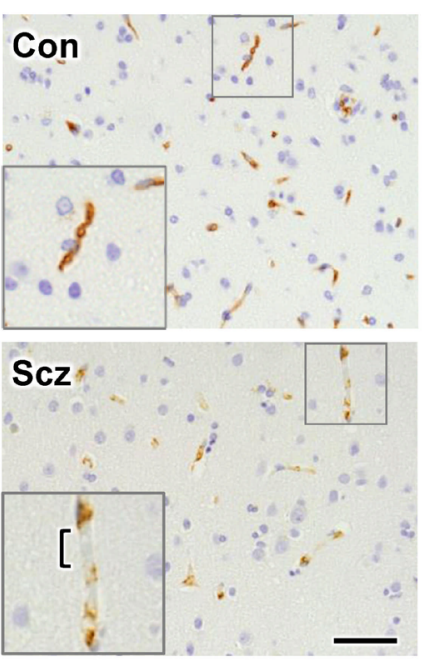

C

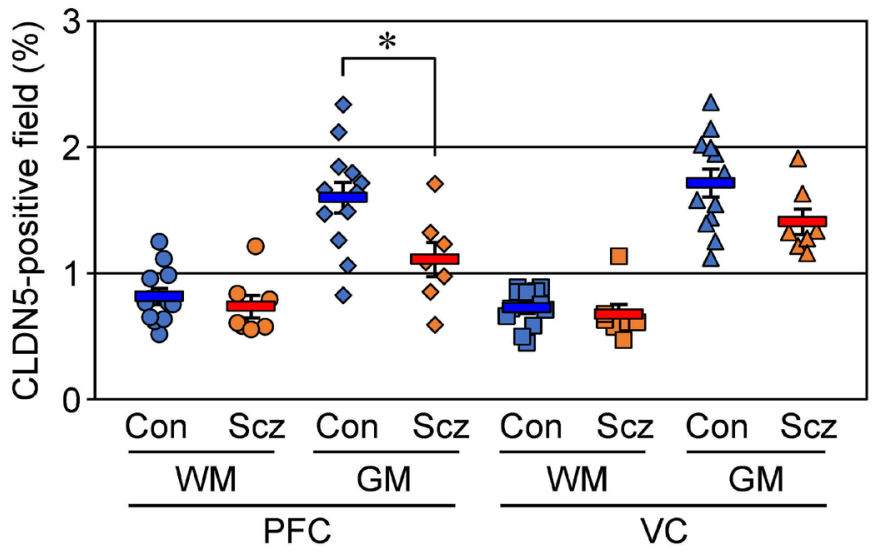

$\mathrm{D}$
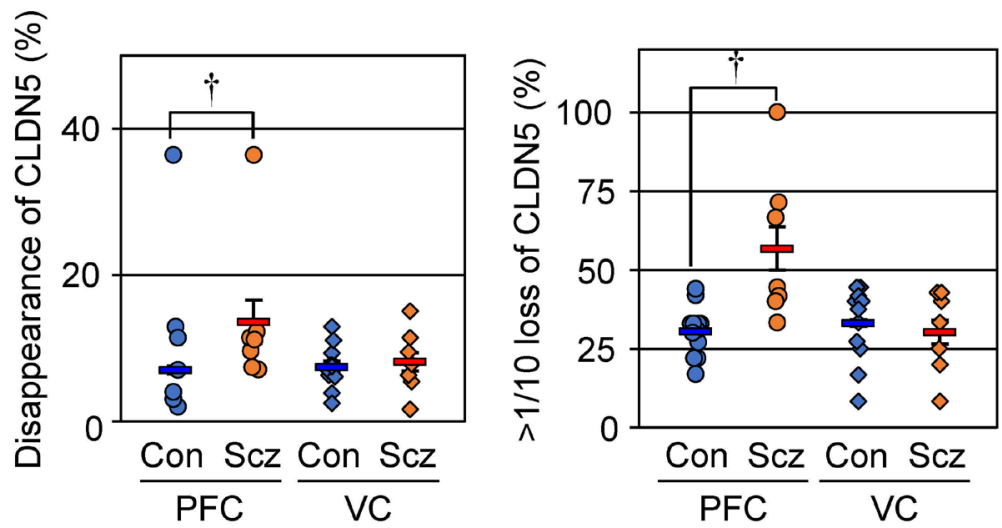

Figure 1: Expression of CLDN5 mRNA and protein is reciprocally modulated in the PFC gray matter of schizophrenia. (A) The mRNA levels of CLDN5 in the indicated brain tissues were determined by real-time PCR, and normalized to the corresponding $G A P D H$ levels. The values are plotted relative to the mean value in the control PFC, which was taken as 1 , and represent the mean $\pm \mathrm{SEM}$ (Con; $\mathrm{n}=12$, Scz; $\mathrm{n}=20$ ). Con; control, Scz; schizophrenia, PFC; prefrontal cortex, VC; visual cortex. $* P<0.05$. (B) The PFC gray matter tissues of Con and Scz subjects were subjected to immunostaining with the anti-CLDN5 antibody. Bracket indicates the discontinuous CLDN5-immunoreactivity. Scale bar, $50 \mu \mathrm{m}$. (C) The percentages of CLDN5-positive field are plotted, and the mean \pm SEM (Con; $\mathrm{n}=12$, Scz; $\mathrm{n}=7$ ) are represented. GM; gray matter, WM; white matter. $* P<0.05$. (D) The percentages of both CLDN5 disappearance and over $1 / 10$ loss of CLDN5 signal in the vessel length axis are plotted, and the mean \pm SEM (Con; $\mathrm{n}=12, \mathrm{Scz} ; \mathrm{n}=7$ ) are represented. ${ }^{\dagger} P<0.01$. 
in the gray matter were higher than those in the white matter in both groups, which most likely corresponds to a well-known physiological difference between the two brain regions.

\section{PKA is activated in the schizophrenic PFC}

We previously showed that cAMP activated PKA to phosphorylate Cldn5 protein in cultured porcine and rat endothelial cells, resulting in size-selective loosening of the endothelial barrier, and that it simultaneously elevated the levels of Cldn5 mRNA in a PKA-independent manner $[27,28]$. Therefore, we hypothesized that the discrepancy between mRNA and protein expression of CLDN5 in the schizophrenic PFC could be caused by similar molecular mechanisms. To verify whether PKA is activated in the PFC microvessels of schizophrenc subjects, frozen sections were immunostained for the phosphorylated catalytic subunit of PKA with CLDN5. As shown in Figure $3 \mathrm{~A}$, the pPKA-immunoreactivity in the PFC of schizophrenic subjects was enhanced compared with

\section{A}
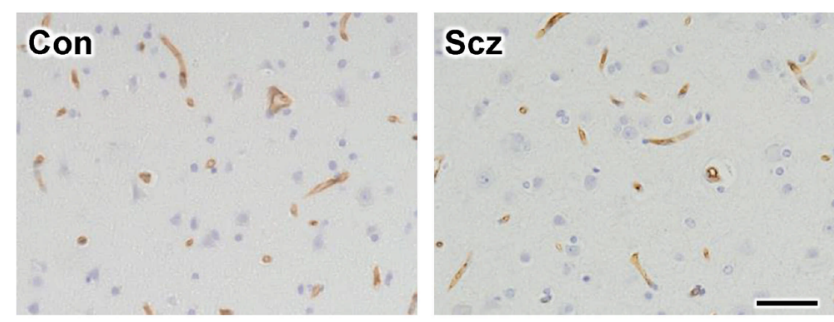

$\mathrm{B}$

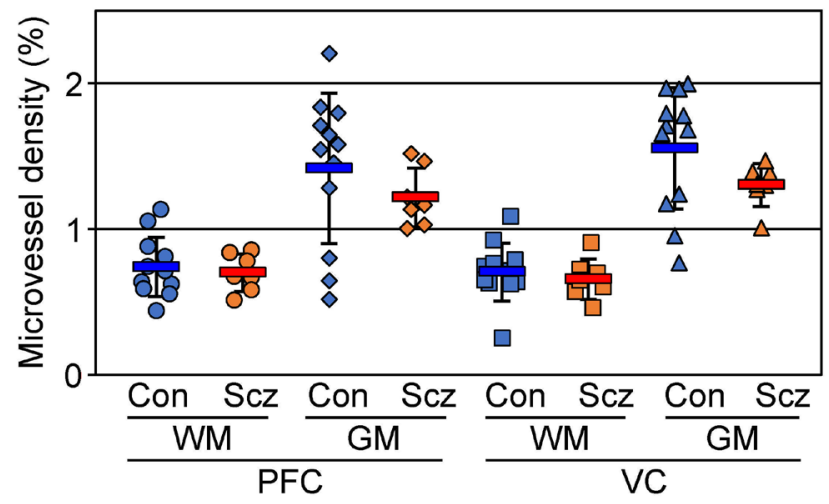

C

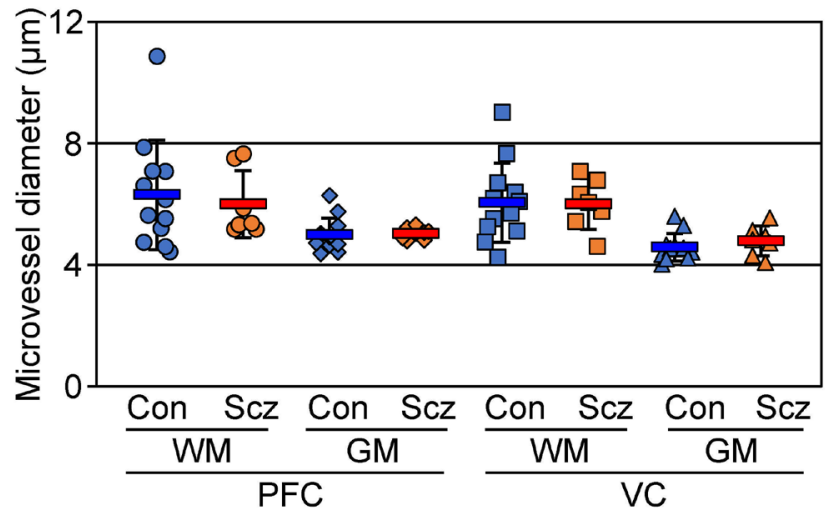

Figure 2: No changes are detected in the microvessel density and diameter of the schizophrenic brain cortex. (A) The PFC gray matter tissues of the control (Con) and schizophrenia (Scz) groups were subjected to immunostaining with the anti-CD34 antibody. Scale bar, $50 \mu \mathrm{m}$. The percentages $(\mathbf{B})$ and diameter $(\mathbf{C})$ of the CD34-positive area are plotted, and the mean $\pm \mathrm{SEM}(\mathrm{Con} ; \mathrm{n}=12$, $\mathrm{Scz} ; \mathrm{n}=7)$ are represented. PFC; prefrontal cortex, VC; visual cortex, GM; gray matter, WM; white matter. ${ }^{*} P<0.05$. 
those of the controls. In addition, the pPKA signals were often distributed close to CLDN5-positive BMVECs, and were at least in part colocalized with CLDN5 (Figure 3A, B). Intriguingly, the pPKA-positive microvessels occasionally exhibited irregular discontinuity of CLDN5immunoreactivity in the schizophrenic PFC (Figure 3B, right). Moreover, quantitative analysis demonstrated that

A
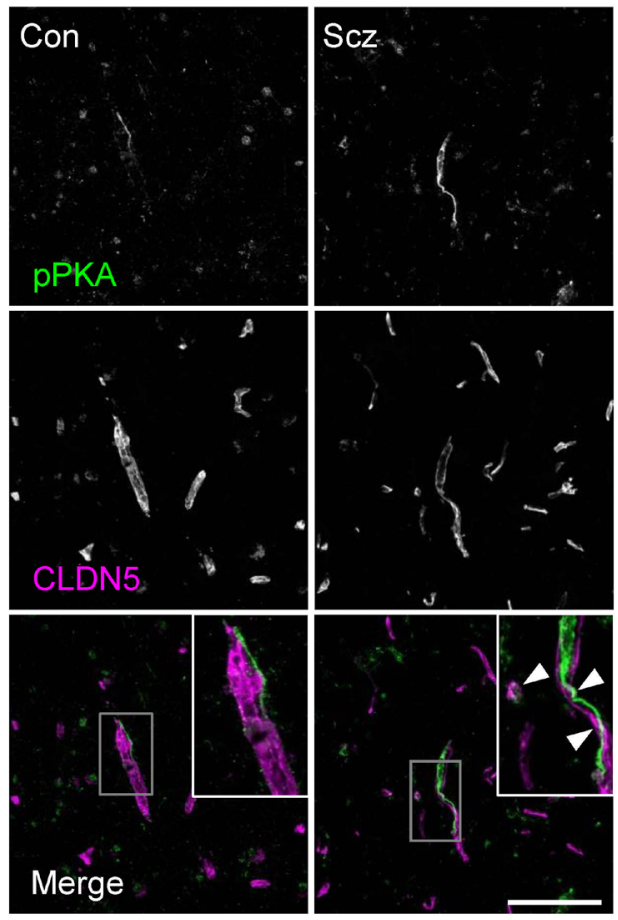

C

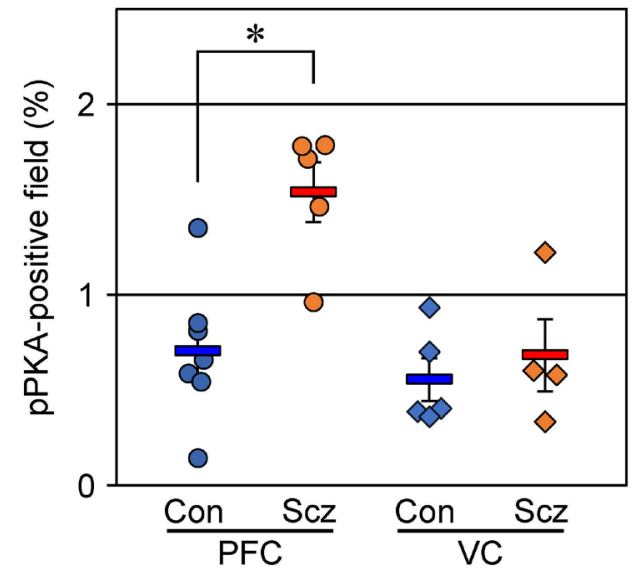

the pPKA-positive field in the schizophrenic PFC was significantly higher than that in the control PFC, and that no differences were observed regarding $\mathrm{VC}$ between the two groups (Figure 3C). Thus, PKA appeared to be selectively activated in BMVECs and the surrounding cells of the schizophrenic PFC, in which CLDN5 breakdown was detected.

B
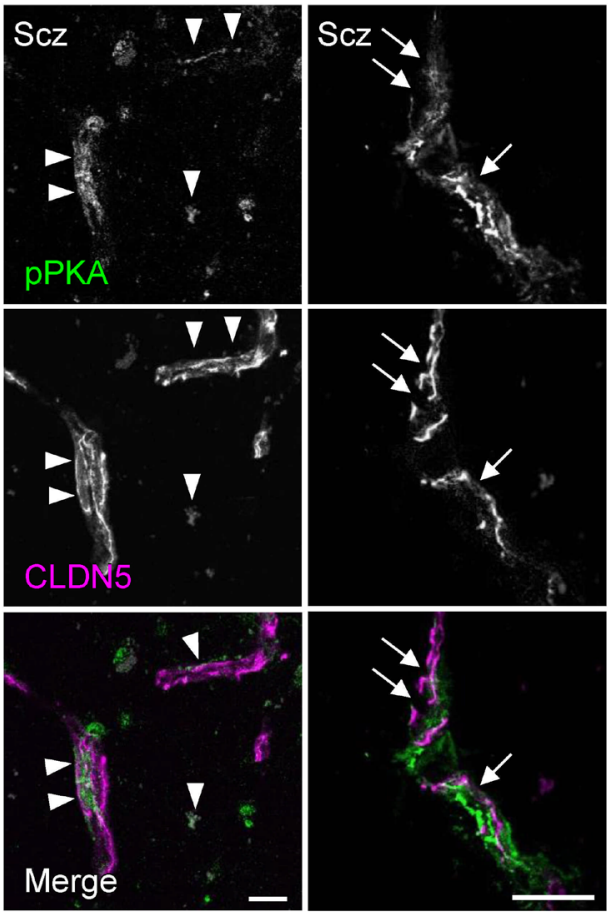

Figure 3: PKA is activated in the PFC of schizophrenia. (A, B) Confocal images of the control (Con) and schizophrenic (Scz) PFC gray matter tissues stained for pPKA with CLDN5. Arrowheads indicate colocalization of pPKA and CLDN5, and arrows show the discontinuous CLDN5-immunoreactivity in pPKA-positive microvessels. Scale bars, (A) $100 \mu \mathrm{m}$; (B) $20 \mu \mathrm{m}$. (C) The percentages of the pPKA-positive field are plotted, and the mean \pm SEM (Con/PFC; n=7, Scz/PFC; n=5, Con/VC; $n=5$, Scz/VC; $n=4)$ are represented. PFC; prefrontal cortex, $\mathrm{VC}$; visual cortex, GM; gray matter, $\mathrm{WM}$; white matter. ${ }^{*} P<0.01$. 


\section{Endothelial barrier against fibrinogen and IgG is maintained in the schizophrenic PFC}

Since CLDN5 contributes to the endothelial barrier against small molecules (less than $800 \mathrm{Da}$ ) but not against larger ones [22], we subsequently checked the extravasation of fibrinogen $(340 \mathrm{kDa})$ and $\operatorname{IgG}(160$ $\mathrm{kDa}$ ) in the PFCs of the schizophrenic and control groups. As suspected, the leakage of these serum proteins from blood vessels was not observed in both groups (Figure 4A, $\mathrm{B})$, indicating that the barrier against large molecules is maintained in the schizophrenic PFC.

\section{DISCUSSION}

CLDN5 is absolutely required for the development and maintenance of the $\mathrm{BBB}$, since the barrier against small molecules (less than $800 \mathrm{Da}$ ) is severely disrupted in CLDN5-null mice [22]. Focal loss of CLDN5 is also associated with the BBB dysfunction in mice [31]. Moreover, a close relationship between the diminished CLDN5 expression in BMVECs and the BBB breakdown has been reported in a range of human neurological disorders $[14,15,17,18]$. Thus, CLDN5 could represent for the tightness of the BBB. In the present study, we found by quantitative immunohistochemical analysis that

A
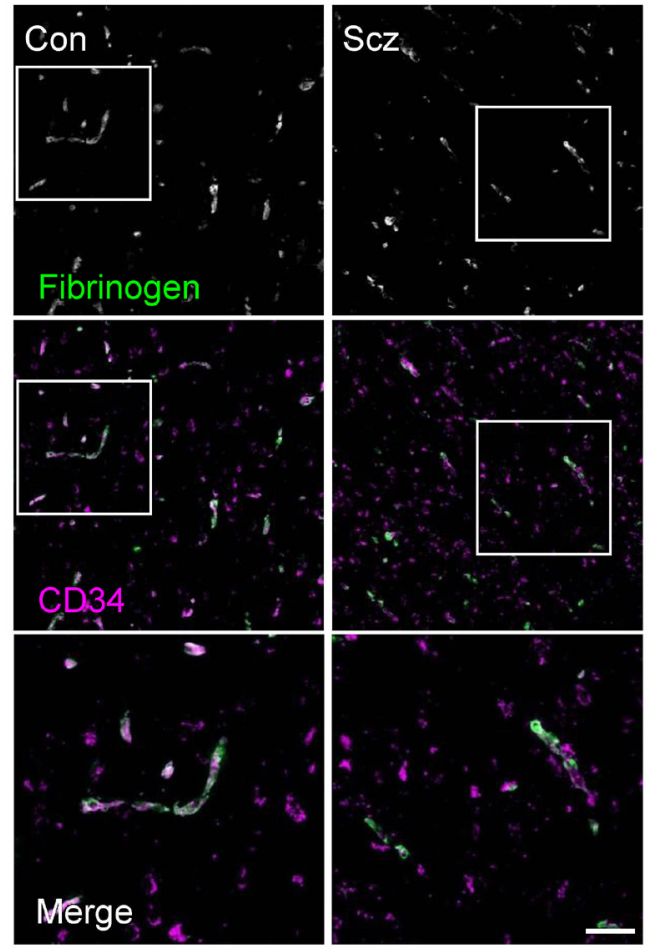

B

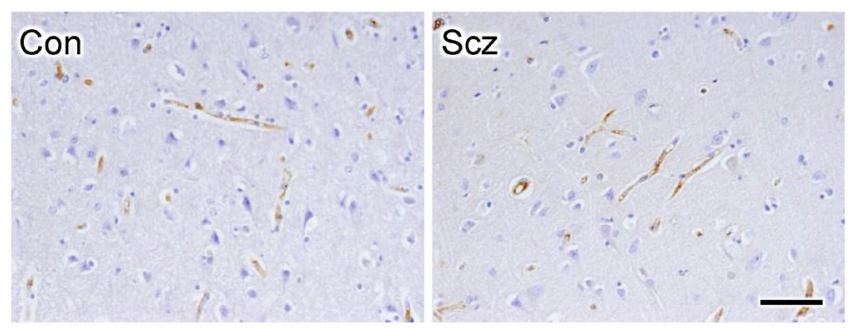

Figure 4: No leakage of fibrinogen and IgG are observed from microvessels in the schizophrenic PFC. (A) Confocal images of the control (Con) and schizophrenic (Scz) PFC gray matter tissues stained for fibrinogen with CD34. (B) Images of Con and PFC gray matter tissues immunostained for IgG. Scale bars, (A) $100 \mu \mathrm{m}$; (B) $50 \mu \mathrm{m}$. 
expression of the CLDN5 protein in microvessels of the schizophrenic PFC gray matter was significantly decreased compared with that in control subjects. By contrast, no differences in CLDN5 protein expression were detected in the $\mathrm{VC}$ white or gray matter between the schizophrenic and control groups. Although we cannot evaluate the leakage of small serum proteins or peptides due to the absence of such endogenous markers, the endothelial barrier against fibrinogen and IgG was well maintained in the schizophrenic PFC, suggesting a lack of the massive BBB breakdown. Taken together, our results indicate that a significant reduction in the expression of CLDN5 protein occurs selectively in the PFC gray matter in patients with schizophrenia, most probably resulting in focal $\mathrm{BBB}$ breakdown for small molecules. Furthermore, brain region-selective $\mathrm{BBB}$ dysfunction may be also involved in the pathogenesis of other neurological disorders.

Interestingly, microvascular and perivascular PKA activation appeared to be observed in the schizophrenic PFC but neither in the schizophrenic VC nor in the control PFC or VC. More importantly, the pPKA-positive BMVECs in the schizophrenic PFC occasionally displayed focal loss of CLDN5. In other words, the activity of PKA and amount of CLDN5 protein were conversely regulated in the microvessels. In this respect, it should be noted that we previously identified a phosphorylation site for PKA at Thr207 in the cytoplasmic domain of CLDN5 [27]. We next generated rat lung endothelial cells expressing doxycycline-inducible wild-type CLDN5 or the CLDN5 mutant with a substitution of Thr207 for an Ala residue, and demonstrated that phosphorylation of this site by PKA caused size-selective loosening of the endothelial barrier [28]. The significance of the phosphorylation of CLDN5 at Thr207 in the BBB breakdown has also been reported in human immunodeficiency virus-1 encephalitis [32]. Thus, we conclude that the enhanced PKA activity could lead to the breakdown of CLDN5 in the BMVECs of the schizophrenic PFC.

Another issue that should be discussed is the discrepancy between mRNA and protein expression of CLDN5 in the schizophrenic PFC. Intriguingly, we previously demonstrated that cAMP induced mRNA expression and Thr207-phosphorylation of CLDN5 in BMVECs in PKA-independent and -dependent fashions, respectively [27]. Since the cAMP signalling [33, 34] and downstream PKA signalling reported in the present study are aberrantly activated in the schizophrenic PFC, this cascade could be responsible for the induced expression of CLDN5 mRNA and the breakdown of CLDN5 protein. Hence, the significant up-regulation of CLDN5 mRNA is detected in the schizophrenic PFC but, nevertheless, the phosphorylation and subsequent degradation of CLDN5 seems to predominate in the induced gene expression.

In conclusion, we found that PKA activation and CLDN5 breakdown occurred in the microvessels of schizophrenic PFC. The molecular mechanism underlying the PKA stimulation is unknown. However, since many different members of $\mathrm{G}$ protein-coupled receptors and their corresponding ligands are known to both positively and negatively regulate the $\mathrm{cAMP} / \mathrm{PKA}$ pathway $[35,36]$, they may contribute to PKA activation in the microvessels of the schizophrenic PFC. Our findings provide new insights into the pathophysiology of schizophrenia.

\section{MATERIALS AND METHODS}

\section{Cases and brain tissues}

Postmortem human brain tissues were obtained from the Fukushima Postmortem Brain and DNA Bank for Psychiatric Research (Fukushima PMB/DNA Bank) and the Niigata University Brain Research Institute. All schizophrenic subjects had been diagnosed according to the DSM-IV (Diagnostic and Statistical Manual of Mental Disorders, Fourth Edition) criteria, and informed consent was obtained from the next of kin for each subject. The schizophrenia and control subjects had no histories of other neurological disorders, alcoholism, or drug abuse, and were matched for sex, age, and postmortem interval as much as possible (Supplementary Table 1). Brains were collected and cut coronally in $10-\mu \mathrm{m}$ slices, from which the PFC (Brodmann area [BA] 10) and the VC (BA17) were dissected. The samples were either stored at $-80^{\circ} \mathrm{C}$ until use or fixed with formalin and embedded in paraffin blocks.

All experimental protocols were approved by the Ethical Committee of Fukushima Medical University and carried out in accordance with relevant guidelines and regulations.

\section{Real-time PCR}

Total RNA was isolated using TRIzol reagent (Invitrogen, New York, NY), and complementary DNAs were produced from $1 \mu \mathrm{g}$ of DNase-treated RNA using a random primer according to the manufacturer's instructions (Takara Bio, Kusatsu, Japan). Target genes were quantified by real-time PCR (StepOne; Applied Biosystems, Foster City, CA) using SYBR Green (Fast SYBR Green PCR Master Mix; Applied Biosystems). The primers used are shown below. All measurements were performed in triplicate, and the expression levels of CLDN5 gene were normalized using the expression of the housekeeping gene $G A P D H$. The relative amount of transcript was estimated by the standard curve method.

CLDN5: product size 302 bp, Refseq; NM_001130861.1

Forward; 5'-CTGTTTCCATAGGCAGAGCG-3'

Reverse; 5'-AAGCAGATTCTTAGCCTTCC-3'

GAPDH: product size 117 bp, Refseq; 


\section{NM_002046.5}

Forward; 5'-TTGTTGCCATCAATGACCCC-3'

Reverse; 5'-TGACAAGCTTCCCGTTCTCA-3'

\section{Immunohistochemistry}

For bright-field immunohistochemistry, tissues were embedded in paraffin and sectioned at a thickness of $4 \mu \mathrm{m}$ with a microtome. Antigen retrieval was subsequently performed by microwaving in $10 \mathrm{mM}$ sodium citrate buffer ( $\mathrm{pH} 6.0$ ) or by incubation with $0.5 \%$ trypsin. After blocking using 5\% skimmed milk (Morinaga Milk Industry, Tokyo, Japan), the sections were incubated overnight at $4{ }^{\circ} \mathrm{C}$ with primary antibodies, rabbit antiCLDN5 (1:200, IBL, Fujioka, Japan; [27]), mouse antiCD34 (1:100, Nichirei, Tokyo, Japan), and rabbit anti-IgG (1:1000, Abcam, Cambridge, MA, USA). After washing with PBS, secondary antibody reaction was performed by using Histofine Simple Stain MAX-PO (MULTI) Kit (Nichirei) with $\mathrm{DAB}$ as a chromogen according to the manufacturer's instructions.

For immunofluorescence staining, sections were prepared at a thickness of $20 \mu \mathrm{m}$ from snap-frozen tissues, and fixed in $100 \%$ methanol for $10 \mathrm{~min}$ at $-20^{\circ} \mathrm{C}$. After blocking with 5\% donkey serum and 2\% bovine serum albumin in either TBS or PBS for $30 \mathrm{~min}$, they were incubated for $1 \mathrm{~h}$ at room temperature with rabbit anti-phosphorylated PKA (pPKA) (1:500, Santa Cruz Biotechnology, Dallas, TX, USA), mouse anti-CLDN5 (1:200, Invitrogen) and rabbit anti-fibrinogen (1:200, Dako, Glostrup, Denmark). They were subsequently reacted with either Alexa fluor 488 donkey anti-rabbit IgG or Cy3 donkey anti-mouse IgG (Thermo Fisher Scientific, Waltham, MA, USA).

All samples were examined and photographed using bright-field microscopy (OLYMPUS BX61, Olympus, Tokyo, Japan) and scanning confocal laser microscopy (FV1000; Olympus). Ten stacks of $0.5-\mu$ m-thick optical slices were collected through the $\mathrm{z}$ axis of tissue sections of regions to be analyzed.

\section{Quantitative morphometric analysis}

For quantification of immunoreactive signals for CLDN5 and CD34, five microscopic fields (magnification $\times 200,440 \times 330 \mu \mathrm{m}^{2}$ ) per region were randomly selected, and immunoreactive area fraction was determined using ImageJ software (ver 1.49). Briefly, DAB-stained images were binarized and the percentage of immunostained area per total area was calculated. The CLDN5-positive vessels with a long axis over 100 pixels $(80 \mu \mathrm{m})$ were also picked out, and the percentage of CLDN5 disappearance was quantified. In addition, blood vessel diameter was also measured (more than 120 vessels from each region) using CD34-stained sections.
For quantification of pPKA signals, five fields (magnification $\times 200,635 \times 635 \mu \mathrm{m}^{2}$ ) per region were randomly chosen, and the immunoreactive area was calculated using ImageJ software.

\section{Statistical analysis}

The statistical significance of differences between the control and schizophrenic groups in each region was evaluated by the Mann-Whitney U tests for the nonparametric analysis, and analyzed by SPSS software (ver. 21, IBM, Armonk, NY).

\section{Author contributions}

KN, NI-T, KS, TI, and HC conceived and designed the experiments, interpreted the data, and prepared the figures. KN, NI-T, KS, and TI carried out the experiments. KK, MT and TS performed some of the immunohistochemical experiments. YK, YY, MH, HY, HT and AK contributed materials, and interpreted the data. TI and HC wrote the paper. All authors reviewed the manuscript.

\section{ACKNOWLEDGMENTS AND FUNDING}

We thank Dr. Junya Matsumoto, Ayumi Hozumi, Tomiko Miura and Keiko Watari for their technical assistance; and English Editing Service, Medical Research Promotion Office, Fukushima Medical University for help with the manuscript. This study was supported by Grants-in Aid for the Ministry of Education, Culture, Sports, Science and Technology of Japan, and by the Collaborative Research Project of the Brain Research Institute, Niigata University.

\section{CONFLICTS OF INTEREST}

Authors declare no conflicts of interest.

\section{REFERENCES}

1. Gottesman S. Bacterial regulation: global regulatory networks. Annu Rev Genet. 1984; 18:415-41.

2. Ellison-Wright I, Glahn DC, Laird AR, Thelen SM, Bullmore E. The anatomy of first-episode and chronic schizophrenia: an anatomical likelihood estimation metaanalysis. Am J Psychiatry. 2008; 165: 1015-23.

3. Meyer-Lindenberg A. From maps to mechanisms through neuroimaging of schizophrenia. Nature. 2010; 468: 194202.

4. Karayiorgou M, Morris MA, Morrow B, Shprintzen RJ, Goldberg R, Borrow J, Gos A, Nestadt G, Wolyniec PS, Lasseter VK. Schizophrenia susceptibility associated with 
interstitial deletions of chromosome 22q11. Proc Natl Acad Sci USA. 1995; 92:7612-16.

5. Murphy KC, Jones LA, Owen MJ. High rates of schizophrenia in adults with velo-cardio-facial syndrome. Arch Gen Psychiatry. 1999; 56: 940-5.

6. Xu J, Fan YS, Siu VM. A child with features of Goldenhar syndrome and a novel $1.12 \mathrm{Mb}$ deletion in 22q11.2 by cytogenetics and oligonucleotide array $\mathrm{CGH}$ : is this a candidate region for the syndrome? Am J Med Genet A. 2008; 146A: 1886-9.

7. Bassett AS, Costain G, Fung WL, Russell KJ, Pierce L, Kapadia R, Carter RF, Chow EW, Forsythe PJ. Clinically detectable copy number variations in a Canadian catchment population of schizophrenia. J Psychiatr Res. 2010; 44: 1005-9.

8. Karayiorgou M, Simon TJ, Gogos JA. 22q11.2 microdeletions: linking DNA structural variation to brain dysfunction and schizophrenia. Nat Rev Neurosci. 2010; 11: 402-16.

9. Guna A, Butcher NJ, Bassett AS. Comparative mapping of the 22q11.2 deletion region and the potential of simple model organisms. J Neurodev Disord. 2015; 7: 18.

10. Insel TR. Rethinking schizophrenia. Nature. 2010; 468: 187-93.

11. van Os J, Kenis G, Rutten BP. The environment and schizophrenia. Nature. 2010; 468: 203-12.

12. Ripke S, Neale BM, Corvin A, Walters JT, Farh KH, Holmans PA, Lee P, Bulik-Sullivan B, Collier DA, Huang H, Pers TH, Agartz I, Agerbo E, et al, and Schizophrenia Working Group of the Psychiatric Genomics Consortium. Biological insights from 108 schizophrenia-associated genetic loci. Nature. 2014; 511:421-27.

13. Alvarez JI, Katayama T, Prat A. Glial influence on the blood brain barrier. Glia. 2013; 61: 1939-58.

14. Obermeier B, Daneman R, Ransohoff RM. Development, maintenance and disruption of the blood-brain barrier. Nat Med. 2013; 19: 1584-96.

15. Daneman R. The blood-brain barrier in health and disease. Ann Neurol. 2012; 72: 648-72.

16. Winkler EA, Bell RD, Zlokovic BV. Central nervous system pericytes in health and disease. Nat Neurosci. 2011; 14: 1398-405.

17. Schoknecht K, David Y, Heinemann U. The blood-brain barrier-gatekeeper to neuronal homeostasis: clinical implications in the setting of stroke. Semin Cell Dev Biol. 2015; 38: 35-42.

18. Gorter JA, van Vliet EA, Aronica E. Status epilepticus, blood-brain barrier disruption, inflammation, and epileptogenesis. Epilepsy Behav. 2015; 49: 13-6.

19. Hanson DR, Gottesman II. Theories of schizophrenia: a genetic-inflammatory-vascular synthesis. BMC Med Genet. 2005; 6: 7.

20. Schoknecht K, Shalev H. Blood-brain barrier dysfunction in brain diseases: clinical experience. Epilepsia. 2012 (Suppl
6); 53:7-13.

21. Morita K, Furuse M, Fujimoto K, Tsukita S. Claudin multigene family encoding four-transmembrane domain protein components of tight junction strands. Proc Natl Acad Sci U S A. 1999; 96: 511-6.

22. Nitta T, Hata M, Gotoh S, Seo Y, Sasaki H, Hashimoto N, Furuse M, Tsukita S. Size-selective loosening of the bloodbrain barrier in claudin-5-deficient mice. J Cell Biol. 2003; 161: 653-60.

23. Sirotkin H, O'Donnell H, DasGupta R, Halford S, St Jore B, Puech A, Parimoo S, Morrow B, Skoultchi A, Weissman SM, Scambler P, Kucherlapati R. Identification of a new human catenin gene family member (ARVCF) from the region deleted in velo-cardio-facial syndrome. Genomics. 1997; 41: 75-83.

24. Sun ZY, Wei J, Xie L, Shen Y, Liu SZ, Ju GZ, Shi JP, Yu YQ, Zhang X, Xu Q, Hemmings GP. The CLDN5 locus may be involved in the vulnerability to schizophrenia. Eur Psychiatry. 2004; 19: 354-7.

25. Omidinia E, Mashayekhi Mazar F, Shahamati P, Kianmehr A, Shahbaz Mohammadi H. Polymorphism of the CLDN5 gene and Schizophrenia in an Iranian Population. Iran J Public Health. 2014; 43: 79-83.

26. Furuse M, Fujita K, Hiiragi T, Fujimoto K, Tsukita S. Claudin-1 and -2: novel integral membrane proteins localizing at tight junctions with no sequence similarity to occludin. J Cell Biol. 1998; 141: 1539-50.

27. Ishizaki $T$, Chiba H, Kojima $T$, Fujibe $M$, Soma $T$, Miyajima H, Nagasawa K, Wada I, Sawada N. Cyclic AMP induces phosphorylation of claudin-5 immunoprecipitates and expression of claudin-5 gene in blood-brain-barrier endothelial cells via protein kinase A-dependent and -independent pathways. Exp Cell Res. 2003; 290: 275-88.

28. Soma T, Chiba H, Kato-Mori Y, Wada T, Yamashita T, Kojima T, Sawada N. Thr(207) of claudin-5 is involved in size-selective loosening of the endothelial barrier by cyclic AMP. Exp Cell Res. 2004; 300: 202-12.

29. Kreczmanski P, Schmidt-Kastner R, Heinsen H, Steinbusch HW, Hof PR, Schmitz C. Stereological studies of capillary length density in the frontal cortex of schizophrenics. Acta Neuropathol. 2005; 109: 510-8.

30. Uranova NA, Zimina IS, Vikhreva OV, Krukov NO, Rachmanova VI, Orlovskaya DD. Ultrastructural damage of capillaries in the neocortex in schizophrenia. World J Biol Psychiatry. 2010; 11: 567-78.

31. Zhou Y, Wang Y, Tischfield M, Williams J, Smallwood PM, Rattner A, Taketo MM, Nathans J. Canonical WNT signaling components in vascular development and barrier formation. J Clin Invest. 2014; 124: 3825-46.

32. Yamamoto M, Ramirez SH, Sato S, Kiyota T, Cerny RL, Kaibuchi K, Persidsky Y, Ikezu T. Phosphorylation of claudin-5 and occludin by rho kinase in brain endothelial cells. Am J Pathol. 2008; 172: 521-33.

33. Muly C. Signal transduction abnormalities in schizophrenia: 
the cAMP system. Psychopharmacol Bull. 2002; 36: 92105.

34. Funk AJ, McCullumsmith RE, Haroutunian V, MeadorWoodruff JH. Abnormal activity of the MAPK- and cAMP-associated signaling pathways in frontal cortical areas in postmortem brain in schizophrenia. Neuropsychopharmacology. 2012; 37: 896-905.
35. Bockaert J, Pin JP. Molecular tinkering of G proteincoupled receptors: an evolutionary success. EMBO J. 1999; 18: 1723-9.

36. Pierce KL, Premont RT, Lefkowitz RJ. Seventransmembrane receptors. Nat Rev Mol Cell Biol. 2002; 3: 639-50. 